\title{
Are there any useful investigations that predict which patients with bifascicular block will develop third degree atrioventricular block?
}

Syncope is a common symptom, particularly in the elderly. In patients with cardiovascular disease, it is associated with a high mortality within the first year. ${ }^{1}$ Therefore, patients with syncope that might be of cardiac origin need thorough investigation, and, if possible, should be offered a reliable treatment. One such treatment for bradyarrhythmias is pacing. The mortality in patients with documented heart block without pacing is about $50 \%$ during the first year. ${ }^{2}$ Second degree heart block has a similar prognosis. ${ }^{3}$

Heart block arises most often in patients with conduction tissue fibrosis, and less often in those with coronary or other heart disease. A less serious form of conduction disease is intraventricular conduction delay in the bundle branches and their various fascicles. None the less, in some cases this form of "minor" conduction disease progresses to complete heart block, often accompanied by syncope or attacks of the type described by Adams-StokesMorgagni. Furthermore, the association of newly acquired bifascicular block and some acute myocardial infarction is related to complete heart block (when a long HV interval is present) and to increased cardiovascular death. ${ }^{4}$

There are many problems associated with bifascicular block. First, because the electrocardiogram often shows normal atrioventricular conduction after syncope we can only be certain that the syncope was caused by heart block. Nor can we predict which patients with bundle branch block (left bundle branch block or right bundle branch block with left hemiblock) will progress to complete heart block. Electrophysiological measurements are often abnormal, but seldom to the extent (in the case of the $\mathrm{HV}$ interval prolonged to $80-100 \mathrm{~ms}$ ) that is associated with a high incidence of progression. Finally, even in patients with severe distal conduction disease, syncope may be caused by other, coexistent abnormalities.

\section{Electrophysiological studies to predict the} development of complete heart block

Scheinman et al proved in 1973 that His bundle recordings could be used to distinguish between those who had neurological symptoms caused by transient high grade atriovenricular (AV) block and those with other causes. ${ }^{5}$ However, it was soon recognised that not all patients with transient AV block had considerable $\mathrm{HV}$ prolongation at the time of study, so that this marker was regarded as specific but not sensitive. ${ }^{6}$ A prospective study of a large group of patients showed that another way of predicting the development of AV block was to record from the His bundle during atrial pacing. ${ }^{7}$ However, few patients $(10 / 496)$ in this observational study progressed to distal AV block, and only six out of 10 patients had block during atrial pacing, making such study unrewarding in most patients.

\section{Pharmacological stress tests}

In 1978 intravenous procainamide was reported to produce high degree heart block in patients with syncope. ${ }^{8}$ Some groups regarded this pharmacological test as a useful method of assessing the need for pacing. Englund et al have recently used an intravenous disopyramide test as a pharmacological stress test (like procainamide, ajmaline, and flecainide) to assess the reserve of the His Purkinje system..$^{9}$ It is clear that the stress test has a higher sensitivity than a test in the baseline state, and this is the merit of the present study. None the less the disopyramide stress test has specific limitations. What advantages does disopyramide have over procainamide, a drug which can be used in a standardised way? Disopyramide does indeed have favourable electrophysiological characteristics, but its haemodynamic profile is not as good as Englund et al suggest. They had only one case of hypotension. Their experience seems to be better than the general experience with disopyramide, which when taken by mouth has a depressant effect on the myocardium. Like others who have studied intravenous disopyramide, ${ }^{1011}$ Englund et al seem to have been lucky. Disopyramide can cause severe hypotension in patients with arrhythmias: some patients have to be resuscitated. It seems premature to suggest that such a test is safe and can be performed outside an electrophysiology laboratory or without a temporary pacemaker.

\section{Should pacemakers be implanted without further study?}

Some advise implantation of a permanent pacemaker without additional studies in patients with symptomatic bifascicular block, or when syncope remains unexplained. ${ }^{512}$ This seems reasonable, but Englund et als arguments for rejecting this option are valid too. ${ }^{9}$ The concept of a pacemaker that detects bradycardia is interesting, but bradyarrhythmias (for example, those caused by sinus node disease) may be sufficient to trigger ventricular pacing. Subsequent retrograde conduction into the AV node might cause anterograde AV block and hence reinforce the need for pacing. Therefore, we must be cautious about relying on information obtained by telemetry of pacemaker data, as was done in Englund et al's study. Prophylactic implantation of a pacemaker in patients with bifascicular block is only appropriate if we can prove that 
these patients need a pacemaker to avoid recurrent symptoms or sudden death. The occurrence of syncope in some patients with a pacemaker in the series reported by Englund $e t$ al is a striking finding.

\section{The real causes of syncope in bifascicular block}

Ventricular tachyarrhythmias are one of the leading causes of syncope. Monitored deaths were caused by ventricular fibrillation rather than heart block. ${ }^{13}$ Poor left ventricular function can also be important in the pathogenesis of syncope. Therefore, the (logical) exclusion of patients with a left ventricular ejection fraction of less than $35 \%$ is a major limitation of Englund et al s study. Earlier studies had already shown that distal conduction disease in combination with congestive heart failure is an indicator of high risk for sudden death. ${ }^{6}$ Thus if patients are studied they should be those with poor ventricular function. A complete study includes not only provocation of heart block with a drug but also programmed electrical stimulation of the ventricle. ${ }^{14}$ If ventricular arrhythmias are induced, there are other treatments. I would be reluctant to implant a pacemaker without additional protective measures in a patient with inducible ventricular tachycardia. $\beta$ blockers which protect against sudden death and are promising in congestive heart failure might be useful. However, it is tempting to consider a transvenous pectoral pacemaker-defibrillator for syncope and inducible ventricular tachycardia. ${ }^{15}$ This will prevent sudden death caused by both bradyarrhythmias and tachyarrhythmias, but will not protect the patient against congestive heart failure.

\section{Conclusions}

In summary, patients with bifascicular block and syncope require further investigation. A disopyramide test may help to avoid unnecessary pacemaker implantations. However, other non-invasive tests (baroreflex sensitivity, tilt table testing) should be considered. ${ }^{16}$ When left ventricular function is poor, the risk of sudden death is high. A disopyramide or procainamide test does not seem to be the investigation of first choice in these patients, but the best strategy to investigate and treat these patients remains unclear. Treatment with $\beta$ blockers (or a pacemakerdefibrillator) is worthwhile considering, even in patients with poor left ventricular function.

Department of Cardiology

University Hospital Ghent,

B 9000 Ghent, Belgium

1 Kapoor WN, Karpf M, Wieand S, Peterson JR, Levey GS. A prospective evaluation and follow-up of patients with syncope. N Engl f Med 1983; 309:197-204.

2 Edhag O, Swahn A. Prognosis of patients with complete heart block or arrhythmic syncope who were not treated with artificial pacemakers: a long term follow-up study of 101 patients. Acta Med Scand 1976;200: 457-63.

3 Shaw DB, Keckwick CA, Veale D, Gowers J, Whistance T. Survival in second degree atrioventricular block. Br Heart $\mathcal{F}$ 1985;53:587-93.

4 Lie KI, Wellens HJ, Schuilenburg RM, Becker AE, Durrer D. Factors influencing prognosis of bundle branch block complicating acute anteroseptal infarction. Circulation 1974:50:935-41.

5 Scheinman M, Weiss A, Kunkel F. His bundle recordings in patients with bundle branch block and transient neurologic symptoms. Circulation 1973;48:322-30.

6 Scheinman MM, Peters RW, Modin G, Brennan M, Mies C, O'Young J. Prognostic value of infranodal conduction time in patients with chronic bundle branch block. Circulation 1977;56:240-4

7 Dhingra RC, Wyndham C, Bauerfeind R, Swiryn S, Deedwania PC, Smith $\mathrm{T}$, et al. Significance of block distal to the His bundle induced by atrial pacing in patients with chronic bifascicular block. Circulation 1979;60: 1455-64.

8 Josephson ME. Intraventricular conduction disturbances. In: Josephson ME, ed. Clinical cardiac electrophysiology: technique and interpretations. Philadelphia: Lea \& Febiger, 1993:141-5.

9 Englund A, Bergfeldt L, Rosenqvist $M$. The disopyramide stress test: a sensitive and highly specific tool for predicting impending high-degree atrioventricular block in patients with bifascicular block. Br Heart $\mathcal{F}$ 1995;74:650-5.

10 Lerman B, Waxman HL, Buxton AE, Josephson ME. Disopyramide: evaluation of electrophysiologic effects and clinical efficacy in patients with sustained ventricular tachycardia or ventricular fibrillation. $\mathrm{Am} ¥ \mathrm{~F}$ Cardiol 1983;51:759-64.

11 Jordaens L, Missault L, Germonpré E, Callens B, Adang L, Vandenbogaerde J et al. Delayed restoration of atrial function after conversion of atrial flutter by pacing or electrical cardioversion. Am $\mathcal{f}$ Cardiol version of atria

12 Altschuler H, Fisher JD, Furman S. Significance of isolated H-V interval prolongation in symptomatic patients without documented heart block. prolongation in symptomatic

13 Cohen HC, Singer DH. Bundle branch block and other forms of aberrant intraventricular conduction: clinical aspects. In: Mandel WJ, ed. Cardiac intraventricular conduction: clinical aspects. In: Mandel

14 Ezri M, Lerman B, Marchlinski FE, Buxton AE, Josephson ME. Electrophysiologic evaluation of syncope in patients with bifascicular block. Am Heart $1983,106: 693-7$.

15 Hammill SC, Stanton MS. Use of the implantable defibrillator. $\mathrm{Br} \mathrm{Heart} \mathcal{f}$ 1995;73:6-7.

16 Farrell TG, Cripps TR, Malik M, Bennet ED, Waed D, Camm AJ. Baroreflex sensitivity and electrophysiological corelates in patients after acute myocardial infarction. Circulation 1991;83:945-52. 